DOI 10.14526/2070-4798-2019-14-1-120-126

\title{
The degree of students' involvement into sports activity determination and evaluation
}

\author{
Aleksandra Yu. Anisimova* \\ Kalashnikov State Technical University, Izhevsk \\ Russia \\ ORCID: 00oo-0002-5899-9123, ffkis@mail.ru*
}

\begin{abstract}
The importance of a person's physical readiness, conditioned by the need for the effective manpower, increases every day. This problem is especially urgent for students, as during the period of studying at a higher educational establishment the basis of a healthy life style are formed. But physical upbringing is not always the priority direction. Materials. The article considers the results of a questionnaire survey. This questionnaire survey studies the degree of students' involvement into educational process of physical upbringing at higher educational establishments. Research methods. Information sources analysis and summarizing, a questionnaire survey, methods of mathematical statistics. Results. The results of the questionnaire survey were the following: 1) the need for physical culture lessons is formed only among 50\% of the 1st course students; 2) the requirements increase for the final certification procedure concerning "Physical culture and sport" discipline for the first course boys in contrast to girls. It is not the factor, which stimulates their sports activity. On the contrary, it causes the reaction of rejection; 3) most students are not interested in different extracurricular sports events. Their involvement into such events will be low; 4) the most difficult kind of activity for students is a sports training; 5) most students don't pay much attention to everyday morning exercises. We revealed the main directions concerning students' involvement into sports activity. Conclusion. In spite of almost similar questionnaire survey results among boys and girls, who study at the first course of Izhevsk State Technical University, there is one difference between them: for girls physical culture and sport lessons are more preferable, than for boys. The boys are inclined to independent trainings. This difference should be taken into consideration during physical upbringing planning and organization at higher educational establishments.
\end{abstract}

Keywords: students, questionnaire survey, physical culture, sports activity.

For citation: Aleksandra Yu. Anisimova*. The degree of students' involvement into sports activity determination and evaluation. The Russian Journal of Physical Education and Sport. 2019; 14(1): 105-109. DOI 10.14526/2070-4798-2019-14-1-120-126

\section{Introduction}

Education modernization in Russia demands an active search for new teaching forms, methods and means. They are directed toward educational process improvement and the oncoming generation training for life and labor in terms of market economy $[1,2,3,4,5,6,7]$. In modern terms educational-upbringing process of students should be directed to new social demands - independent, initiative, creative and healthy personality formation $[8,9,10,11]$. One way to solve this important social demand is the degree of students' involvement into sports activity study $[12,13,14,15,16,17]$.

\section{Results and Discussion}

In order to define the degree of students' involvement into sports activity we held a questionnaire survey. The first-year students of all faculties of Izhevsk State Technical University took part in the survey. We gave 220 questionnaires (25\% of all first-year students (full-time department) -120 boys and 100 girls). As a result, only 213 questionnaires (96,8 \% of general number of questionnaire surveys - 116 boys and 97 girls) turned out to be correctly filled in. The results of the questionnaire survey were handled and then analyzed.

Answering the first question of the 
questionnaire "Will you attend physical culture lessons at a higher educational establishment if they were optional" more than $50 \%$ of boys ( 60 people or $51,7 \%)$ chose the affirmative answer. Other students divided into two not equal groups. Some students, decided not to attend physical culture lessons at all (12,9\%-15 people). $35,4 \%$ of students (41 people) decided to attend physical culture lessons only from time to time. It means that the need for physical culture and sport lessons is formed only among 50\% of boys, who study at the first course.

This conclusion is also proved by the $5^{\text {th }}$ question of the questionnaire: "If the final certification procedure in "Physical culture and sport" were in a form of the examination, would you attend the lessons more often?" The requirements increase for the final certification procedure concerning "Physical culture and sport" discipline don't increase the amount of first-year students with a steady need for this kind of activity. 51,7\% of students (6o people) said "Yes" answering this question. At the same time, the number of negative answers with the requirements increase also increased till 31,0\% (36 people), more than twice. It means that the requirements increase is not the reason, which stimulates first-year male students' sports activity. It is the reason for the rejection reaction.

Answering the second question of the questionnaire "Is it interesting for you to take part in different sports events, which are held at a higher educational establishment?” only $20,7 \%$ of boys (24 people) gave affirmative answers. Equal number of students chose the answer "No" and "Sometimes" $39,6 \%$ of students ( 46 people) each. It means that most boys are not interested in extracurricular sports events and their involvement into such kind of events is minimal.

This conclusion is proved by the results of the 6th question: "Is participation in sports events of a higher educational establishment a significant event for you?" Almost half of first-year students $(44,8 \%$, or 52 people) expressed their negative attitude. $31,0 \%$ of respondents (36 people) chose the answer "sometimes".

One of the possible reasons why first106 sports events is connected with the fact that in most schools not much attention is paid to this kind of activity. It means that sports events are not held systematically. They are not interesting and attractive for schoolchildren.

Answering the 3rd question: "Would you like to go in for sports sections and take part in different competitions?" 33 students ( $28,5 \%$ of the sampling) gave an affirmative answer. Most first-year students don't want to go in for sports -46 people $(39,6 \%$ of the sampling). The rest of boys $(31,9 \%)$ would chose this kind of sports activity only sometimes. It means that the need for sport is not formed among all male students of the first course.

This conclusion is proved by the following question results: "If you took part in all kinds of sports activity, which of them would be the most undesirable for you?" Almost one third of students (38 people or $32,8 \%$ of the sampling) mentioned sports training. 51 people $(44,0 \%)$ answering the 11th question, mentioned that sports training was the most difficult kind of activity for them.

Nevertheless, most male students (91 people or $78,4 \%$ ), answering the question "Would the victory at sports competitions bring you satisfaction? " chose the affirmative answer.

Answering the $5^{\text {th }}$ question "Have you ever gone regularly in for physical exercises and sport?" 44 people $(37,9 \%)$ gave the affirmative answer. 21 students $(18,1 \%)$ don't go in for regular physical exercises. The rest of the first-year students only sometimes go in for this kind of activity (51 people, $44,0 \%)$.

Nevertheless, the students' inclusion into independent physical exercises and sport among the first-year students takes the second position after academic studies. This is also proved by the 1oth question "Which kind of sports activity is the most important for you?" More than one third of students (41 people or $35,3 \%$ ) mentioned this kind of sports activity. However, more than half of students don't do morning exercises every day (62 people or $53,4 \%)$.

Moreover, answering the 12th question: "Which kind of sports activity prepares you for your future professional activity most of all?", 47 people (40,6 \%) chose independent physical exercises and 
sport.

Thus, we come to the conclusion that the inclusion of the 1st-year male-students from Izhevsk State Technical University into all kinds of sports activity is $24,7 \%$. This is their participation index in sports events, held by a higher educational establishment. $28,5 \%$ of students are included into three kinds of sports activity (without sports events). This is the participation index of students in sports sections and competitions. 37,9\% of first-year malestudents are included into two sports activities. This is the index of going in for independent physical exercises and sport. $51,7 \%$ of students go in for one kind of sports activity (physical culture and sport academic studies). $35,4 \%$ of the first-year male-students are sometimes involved into sports activity. $12,9 \%$ of the first-year students would have ignored sports activity, but for physical culture and sport lessons.

Answering the first question of the questionnaire "Would you attend physical culture lessons at a higher educational establishment if they were optional?", less than half of first-course female students (44 people or $45,3 \%$ ) chose the affirmative answer. It is $6,4 \%$ less than among male students. 39 girls $(40,3 \%)$ mentioned the answer "sometimes". 14,4\% of students (14 people) said that they wouldn't attend physical culture lessons. It is $1,5 \%$ more than among male first-year students. It means that the need for physical culture lessons is formed among 50\% of female students, as well as among male students, others don't have such kind of need.

However, answering the $5^{\text {th }}$ question of the questionnaire "If the final attestation were in the form of Physical culture and sport exam, would you attend the lessons more regularly?" $67,0 \%$ of female students chose the affirmative answer. It means that the increased demands concerning the final certification in "Physical culture and sport" discipline is an effective factor, which stimulates their sports activity.

Answering the question "Do you have the interest and desire to take part in different sports events held at a higher educational establishment?" only $18,6 \%$ of female students (18 people) gave the affirmative answer. It is less than among male students of the same course. Sometimes the interest in such kind of events show 21,6\% of girls (21 people), but most respondents (58 people or 59,9 \%) chose the negative answer. It proves that both male and female students show no great interest in extracurricular sports events and their involvement into them would be minimal.

This conclusion is proved by the answers of the 6th question "Is taking part in sports events of a higher educational establishment an important thing for you?" More than half of female students of the 1st course ( $56,8 \%$, or 55 people) expressed their negative attitude. $24,7 \%$ of respondents (24 people) mentioned the answer "sometimes". The reason for such kind of attitude among first-year female students to different sports events is most probably the same as among male students.

Answering the 3rd question "Would you like to go in for sports section and take part in different competitions?" 24 girls $(24,7 \%)$ gave affirmative answer. However, more than $50 \%$ of female students don't want to go in for sports - 52 people (53,7\%). 21,6 \% of girls said that they would prefer this kind of sports activity only sometimes. Among girls the percentage of those, who don't want to go in for sports is $14,1 \%$ higher than among boys. It means that female students of the first course from Izhevsk State Technical University have even lower motivation and the need for physical culture lessons than male students of the same course.

This is proved by the answers of the 9th question "If you took part in all kinds of sports activity, which of them would be the most undesirable for you?" 35 students $(36,2 \%)$ chose sports training. 42 first-year female students $(43,4 \%)$ mentioned that sports training was the most difficult kind of activity for them.

Nevertheless, most girls of the first course (62 people or $63,9 \%$ ) said "yes" answering the 7 th question: "Would you be satisfied with the victory in sports competitions?" The same situation was among boys.

29 people $(29,9 \%)$ said "yes" answering the following question: "Do you regularly go in for physical exercises and sport independently?" This is $8,0 \%$ less than among boys. $32,0 \%$ of girls don't go in for physical exercises and sport regularly. 51 girls 
$(44,0 \%)$ are involved into this kind of sports activity only sometimes.

Nevertheless, the involvement of female and male students into independent physical exercises and sport takes the second place after academic studies. It is proved by the 1oth question "Which kind of sports activity is the most significant and important for you?" 30 people (30,9 \%) mentioned this kind of sports activity. However, both boys and girls don't pay much attention to everyday morning exercises (66 people, $68,0 \%$ ).

Answering the 20th question "Which kind of sports activity most of all trains you for professional activity?" 38 girls $(39,2 \%)$ chose physical culture lessons and sport and this differs them from boys sampling, who preferred independent lessons.

\section{Conclusion}

Thus, analyzing the results of the questionnaire survey among female students of the first course from Izhevsk State Technical University, we come to the conclusion that the degree of their involvement into all kinds of sports activity is $18,5 \%$. This is the index of their participation in sports events. It is held by a higher educational establishment. It is $6,2 \%$ lower than the boys' results. The part of students, who are involved into three kinds of sports activity (without sports events) is $24,7 \%$. This is the index of students' participation in sports sections and competitions. $29,9 \%$ of girls of the first course are involved into two kinds of sports activity.

This is the index of independent physical exercises and sport. 45,3\% of female students go in for one kind of sports activity (academic physical culture lessons). $14,4 \%$ of female students of the 1st course would have ignored sports activity, but they are for compulsory physical culture and sport lessons at a higher educational establishment.

Prospective directions concerning students' involvement into sports activity are the following:

- involving into different sports lessons and participation in competitions;

-involving into different sports events, held at a higher educational establishment.

It should be noted that in spite of great (first-year students of the Izhevsk State Technical University) there is a vital difference between them: for girls physical culture and sport lessons are more preferable, than for boys, who like independent lessons. This difference should be taken into consideration while planning and organizing physical upbringing at higher educational establishments.

\section{References}

1. Alferov A.G. Physical upbringing in humanitarian higher educational establishments in terms of dialogue as the base for education, oriented toward a student's personality. Candidates' thesis. Moscow. 2003: 24.

2. Alkova S.Yu. Pedagogical conditions of the differentiated approach realization in physical upbringing on the basis of students' subjective experience. Candidates' thesis. Moscow. 2002: 24 .

3. Belskiy I.V. The peculiarities of body-building methodology in terms of students' free time. Candidates' thesis. Minsk.1989: 22.

$$
\text { 4. Bogdanov O.A. Generally }
$$

developing gymnastic exercises use for aerobic endurance development among female students. Candidates' thesis. Saint-Petersburg. 1992: 22.

5. Verushkin N.G. Methods and means of physical training management among students of technical higher educational establishments. Candidates' thesis. Moscow. 1996: 22.

6. Vinokurov Y.I. The peculiarities of lessons with first-year students by means of bodybuilding taking into account their constitution, motional motoricity. Candidates' thesis. Tula. 2004: 22.

7. Egorov D.E. Technology of stageby-stage physical readiness level increase among female students of humanitarian profile. Candidates' thesis. Khabarovsk. 2000: 22.

8. Ezhkov V.S. Professional-applied physical training of students of engineering specialties on the basis of main psycho-physiological characteristics of an individual. Candidates' thesis. Moscow. 2003: 24.

9. Nagovitsin S.G. The system of competencies formation in the sphere of physical 
culture during training students at a higher educational establishment. Candidates' thesis. Naberezhnye Chelny. 2013: 50.

10. Solovev G.M., Prokopenko T.I. Health centers as organizational-pedagogical factor and condition for students' healthy life-style formation. Teoriya i praktika fizicheskoi kultury Theory and practice of physical culture. 2001; 9: 4851 (In Russ., In Engl.).

11. Yakimovich V.S. Projecting the system of physical upbringing of students on the basis of personality oriented education. Doctor's thesis. Moscow: VNIIFK. 2002: 48.

12. Andersen L.B., Riddoch C., Kriemler S., Hills A. Physical activity and cardiovascular risk factors in children. British Journal of Sports Medicine. 2011; 45(11): 871-876. DOI: 10.1136/ bjsports-2011-090333.

13. Aznar S., Naylor P.J., Silva P., Perez M., Angulo T., Laguna M., ..., Lopez-Chicharro J. Patterns of physical activity in Spanish children: A descriptive pilot study. Child: Care, Health

Submitted: 18.01.2019

Author's information:

Aleksandra Yu. Anisimova* - Candidate of Pedagogics, associate professor, Kalashnikov State Technical University, Izhevsk, Russia, 426069, Studencheskaya Str., House 7B, e-mail: ffkis@mail. $r u^{*}$ and Development. 2011; 37(3): 322-328. DOI: 10.1111/j.1365-2214.2010.01175.x.

14. Fairclough S.J., Stratton G. 'Physical education makes you fit and healthy'. Physical education's contribution to young people's physical activity levels. Health Education Research. 2005; 20(1): 14-23. DOI: 10.1093/her/cyg101.

15. Hallal P.C., Andersen L.B., Bull F.C., Guthold R., Haskell W., Ekelund U. Global physical activity levels: Surveillance progress, pitfalls, and prospects. The Lancet. 2012; 380(9838): 247-257. DOI: 10.1016/So140-6736(12)60646-1. prospects for physical education in the European union. Brussels: European Parliament Directorate General Internal Policies of the Union. 2007.

17. McKenzie T.L., Sallis J.F., Kolody B., Faucette F.N. Long term effects of a physical education curriculum and staff development program: SPARK. Research Quarterly for Exercise and Sport. 1997; 68(4): 280-291. DOI: 10.1080/02701367.1997.10608009.
16. Hardman K. Current situation and 